\title{
LAS CONEXIONES ENTRE EL PENSAMIENTO DE ALEJANDRO MALASPINA Y LA REPRESENTACIÓN VISUAL DE LA EXPEDICIÓN EN LA PATAGONIA (1789-1794)
}

GABRIELA S. ÁLVAREZ G.

\section{RESUMEN}

El objetivo del trabajo es estudiar la expedición al mando de Alejandro Malaspina (1789-1794) específicamente, su paso por la Patagonia. Observar cómo coincide la formación profesional del capitán con el imaginario dieciochesco en España, y aventurar una explicación al trabajo visual de José del Pozo sobre los indígenas del sur. Revisar qué elementos del arte neoclásico están presentes en sus registros visuales, además de verificar los nexos con el pensamiento malaspiniano, en lo que respecta a la evaluación de la situación colonial en América.

PALABRAS CLAVES: Imaginario, representación visual, arte neoclásico, Patagonia.

\section{THE CONNECTIONS BETWEEN THE THOUGHT OF ALEJANDRO MALASPINA AND VISUAL REPRESENTATION OF THE EXPEDITION IN PATAGONIA (1789-1794)}

\begin{abstract}
The aim of this work is to study the expedition led by Alejandro Malaspina (1789-1794) and specifically its passage through Patagonia. See how his professional training coincides with the imaginary predominant in Spain during the XVIIIth century, and adventure an explanation for the visual work of José del Pozo on the indigenous people of the south. Check which neoclassical art elements are present in their visual records, in addition to the links with the thought of Malaspina, regarding the evaluation of the colonial situation in America.
\end{abstract}

KEYWORDS: Imaginary, visual representation, neoclassical art, Patagonia. 


\section{INTRODUCCIÓN}

Gran parte de la navegación española hacia América transcurrió por las costas patagónicas. Al parecer, el mito de la tierra indócil habitada por gigantes constituye una imagen obsesiva que el europeo desea y rechaza a la vez (Bhabha, 2002:111-119)1, así como, los intentos por instalar una colonia que se frustran debido a la complejidad del clima que exige una revaloración distinta de la zona, lección no comprendida a tiempo por estas exploraciones. De esta manera, los informes de viaje afirman el sentido desértico-hostil de la tierra y la espectacularidad de sus habitantes para poder justificar de alguna forma sus fracasos.

La organización visual que construye al "otro" se articula según el modelo cultural que enmarca los viajes hacia la zona americana. La reiteración de mitos, imágenes o tópicos son parte de un proceso de construcción social que permiten a los sujetos percibir lo real (los imaginarios sociales). En otras palabras, son composiciones sociales de ordenación de la percepción (Baeza, 1995: 13:35) que remite su campo de acción al plano de la representación: únicamente es viable dar cuenta de los imaginarios en y a través de la materialización discursiva en términos concretos (las representaciones). En otra esfera, Lacan reflexiona sobre los imaginarios en el área del inconsciente, describe este concepto como "el discurso del Otro", expuesto en las expresiones ocultas de deseo, la experiencia del sujeto y las significaciones asignadas a la realidad (los puntos de vista) (Gómez, 2001: 195-209). ${ }^{2}$

El objetivo del trabajo es estudiar la expedición al mando de Alejandro Malaspina (1789-1794) específicamente, su paso por la Patagonia. Observar cómo coincide la formación profesional del capi-

1 Homi Bhabha resalta este sentido de ambivalencia en la actitud del sujeto colonial frente al otro, como la figura del mimetismo, que es una forma de representación del reconocimiento de la diferencia y a su vez de renegación, por el deseo de ver al otro reformulado a la altura de los patrones institucionales.

2 Autor que cohesiona un criterio común entre el ámbito de la sociología constructivista del conocimiento (Durkheim, Luckman, Bourdie, Castoriadis, entre otros) y el psicoanálisis lacaniano, con el fin de establecer un marco conceptual más preciso que permita deslindar categorías para realizar un análisis concreto en la sociedad en particular, en el plano simbólico (proceso de producción de sentido y su relación con las prácticas culturales). tán con el imaginario dieciochesco en España y aventurar una explicación al trabajo visual de José del $\mathrm{Pozo}^{3}$ sobre los indígenas del sur, dibujados tradicionalmente como gigantes. Las hipótesis de lectura son: primera, la pintura de José del Pozo responde a las categorías estéticas del neoclasicismo que articula los ideales de la ilustración, la razón junto a los planteamientos clásicos que confluyen en repensar lo antiguo de otra manera. Tal reevaluación, abarca también el papel de la monarquía española en relación a las colonias americanas por tanto, la segunda hipótesis es: el pensamiento de Alejandro Malaspina -basado en esta estimación- refuerza $e$ influye en todos los estamentos (incluyendo el pictórico) sus posiciones políticas-científicas que, desplaza el mito monstruoso del patagón para instalar la imagen del "buen salvaje".

Antecedentes del viaje: los límites culturales de un siglo en transición.

El siglo XVIII es un período de decadencia de la monarquía española, debido a las desventajas frente al poderío que comienza ostentar otras naciones europeas, en particular sus avances en la técnica y el comercio. Sin embargo a nivel de pensamiento, la relación con otras formas de organización de la realidad enfrenta momentos claves de la modernidad a partir de la constitución política de la diversidad, las presunciones de la actividad científica y su poderosa institucionalización, entre otros aspectos (Manfredi, 1994: $11-17){ }^{4}$

Algunos hitos sociopolíticos y culturales interesantes de destacar son las fuerzas libertarias de las colonias de Norteamérica -en 1776-y el inicio de la revolución francesa -1789- que con sus postulados de libertad, igualdad y fraternidad influyen en la formación de una conciencia criolla en las colonias americanas. El contrabando instalado con los holandeses, ingleses y franceses, es un tema que desespera a los funcionarios españoles incapaces de controlar esta peligrosa conexión con sus reinos ultramarinos. Y en la región patagónica, Carlos III firma el 23 de marzo de 1778 la Real Cédula para emplazar algunas colonias; Antonio de Viedma fundará así Carmen de Patagones a orilla del río Negro,

3 Pintor sevillano que fue parte de misión española hasta mediados de 1790

4 Ver introducción de Felipe de la Sota Ríus. 
su hermano Francisco Floridablanca, próxima a la bahía de San Julián, y Juan de la Piedra, el Fuerte de San José en el golfo del mismo nombre (Instituto Panamericano de Geografía e Historia, 2004). En síntesis, la pérdida del poder monárquico se manifiesta con la insubordinación de las colonias, la falta de respuestas efectivas a la complejidad económica, y la carencia evaluativa de los asentamientos políticos en puntos específicos de la geografía americana. Tales eran los ejes en la exposición de Malaspina para convencer a la Corona de llevar a cabo esta expedición.

El grado de influencia de la Armada Española crece sustancialmente durante el poderío de los Borbones, debido al conocimiento avanzado en materias que compete a la Corona. La Guardia Marina, reestructura los planes de formación de sus oficiales -entre ellos Malaspina- activo participante en la construcción del Observatorio y más tarde, en la configuración del curso de Estudios Mayores (Pimentel, 1994) ${ }^{5}$ que, delimita el nuevo perfil de estudiante: oficial de marina experimentado en la navegación con una sólida formación científica. El ministro de Marina -Antonio Valdez- formado con esta visión, percibe la necesidad de organizar el comercio indiano, sistematizar las rutas comerciales y acopiar información (datos estadísticos y revisión de archivos cartográficos), en la necesidad de afrontar la crisis económica en España. Su primer paso, es solicitar al brigadier Vicente Tofiño la confección del Atlas Marino de España en 1787; la expedición de Malaspina sería una prolongación de esta tarea con el atlas marino peninsular:

(...) el fin perseguido es, ni más ni menos, que la configuración del modelo geopolítico representativo de los reinos ultramarinos de la Monarquía, echando manos para su elaboración no sólo de los instrumentos -conceptuales y materiales- que ofrece la ciencia moderna, sino también del contenido neohistórico que arrastra la vieja Monarquía hispánica (Ministerio de defensa. Museo Naval, 1987).

Tradicionalmente, se destaca de la empresa de Malaspina el alto nivel alcanzado por la Armada Imperial, sumado a su capacidad de síntesis sobre un conjunto de proyectos cientificistas que impulsa la

5 Materias que imparten este curso: geometría, física teórica y experimental, astronomía y curso de avanzada en la filosofía natural. corona española durante el siglo XVIII. (De la Sota en Manfredi, 12). Principalmente, resalta la acción investigativa dirigida a reformular las concepciones erradas de la sociedad colonial, la ampliación del conocimiento marítimo y la búsqueda de rutas comerciales efectivas; una especie de estado de la cuestión:

En la expedición Malaspina se entrelazan tres proyectos distintos en una sola acción: el proyecto peninsular, nacido en la élite ilustrada de la Armada y la Secretaría de Marina e Indias, el proyecto intelectual de su comandante, un italiano que reúne en su formación los intereses de toda una época, y finalmente, el descubierto por el viaje, el mundo criollo americano (De la Sota en Manfredi, 1994:12).

Sin exaltar la figura del capitán Malaspina, su enfoque de la realidad española-americana construye los pilares del viaje en la forma de mirar y recolectar la información. El preocuparse personalmente en la elección de los tripulantes, de redactar no sólo la bitácora del viaje, sino también, sus fundamentos ${ }^{6}$, nos lleva a destacar su presencia omnipotente en las distintas disciplinas que apropian sus postulados en cada informe y dibujo sobre lo observado.

El 10 de septiembre de 1788, Malaspina escribe al ministro de Marina e Indias Antonio Valdez y Bazán sus argumentos para emprender el viaje hacia América. En la carta redacta los objetivos, la factibilidad del viaje -aparejos y tripulantes- como los detalles témporo-espaciales del itinerario a llevar a cabo:

(...)el uno es la construcción de cartas hidrográficas para las regiones más remotas de América y de derroteros que puedan guiar con acierto la poca experta navegación mercantil; y el otro, la investigación del estado político de América, así relativamente a España como a las naciones extranjeras (Malaspina en Sagredo y Gonzáles, 2004:162).

El primer objetivo es calificado por el capitán de científico-público, su finalidad es recoger información de la historia natural y botánica de América para el Real Gabinete y el Jardín Botánico. El segundo en cambio, es político-secreto, a base de especulaciones que permita a la Corona realizar un catastro de los

6 Incluso redactó el manual de comportamiento y la dieta alimenticia para evitar el escorbuto. 
establecimientos coloniales como sus fortalezas en el plano económico, y sus condiciones para resistir una invasión enemiga. ${ }^{7}$

El plan inicial de la expedición era dar la vuelta al mundo y retornar a Cádiz en 1793; sin embargo, se extiende por dos años debido a la necesidad de profundizar en las tareas hidrográficas y cartográficas, consideradas útiles según Malaspina para los fines estratégicos perseguido por España:

(...) ya en la división propuesta de tareas se deja ver que deberemos sacrificar a la perfección del trabajo emprendido y al mayor lustre del honor nacional, no solo la materialidad de completar la vuelta alrededor del globo, sí también el reconocimiento del estrecho de Malaca y sobre todo el término del viaje, que nos habían prefijado para 1793 (Malaspina en Ministerio de Defensa. Museo Naval, 1987:147).

Al menos en dos ocasiones, ${ }^{8}$ la empresa española incursiona en los alrededores de la zona patagónica en la búsqueda de asentamientos extranjeros que violaran los dominios españoles. El control constante es complejo, por la falta de coordinación y recursos suficientes de los virreinatos, enfrentados diariamente a vicisitudes en la capacidad de mantener los reductos. El interés del capitán por las tierras australes se cruza con sus objetivos autoasignados, ya que inspeccionar el estado de las colonias españolas y verificar en terreno las intervenciones extranjeras, responden a sus fundamentos estratégicos-comerciales:

Para ellos Chile no sólo fue un finis térrea geográfico, sino también una periferia en la cual comenzaba a usar, a desdibujarse la presencia española en América, con todos los potenciales riesgos y amenazas que esta realidad podía tener para la corona española (Sagredo y Gonzáles, 2004: 27).

La articulación de las distintas áreas del conocimiento no se ubica en la simple constatación empírica de la realidad, sino en avanzar en la configuración del investigador, propuestas a base

7 La Monarquía teme perder esas tierras y el control marítimo debido al constante paso de naves francesas e inglesas en las costas patagónicas.

8 De acuerdo a los mismos antecedentes que redacta Malaspina, los barcos se dividen y abordan esta franja territorial rodeando cabos, islas y puertos para recopilar antecedentes hidrográficos, pero también, observar la existencia de colonias inglesas. del material generado por sus antecesores es decir, las lecturas previas sobre el espacio patagónico (Pimentel, 1994: XV).

Marcas del pensamiento ilustrado en Alejandro Malaspina.

Malaspina conoce cabalmente la tradición marítima española; no obstante, realiza un giro innovador cuando relee los diarios y cartografías de sus antecesores al proyectar sus ideas a través de un aparataje intelectual ilustrado. El espacio americano es la oportunidad de confirmar una línea de pensamiento que recae en su experticia como oficial científico unido a ser un sujeto proyectista. El proyectismo (Pimentel, 130) tiene sus causas en los conflictos ultramarinos y el incremento de las necesidades fiscales del despotismo ilustrado. Su estructura discursiva es la reflexión pragmático-utilitaria y el historicismo como herramienta para explicar las razones de la situación presente: criticar el papel político de la monarquía; el área de la economía será la excusa y el remedio a la vez. Género elaborado por los peninsulares durante el siglo XVIII, cuyo objetivo es denunciar e intentar corregir los errores de fondo del mal manejo de la corona española en sus distintos ámbitos. Malaspina práctica el proyectismo con el texto Axiomas políticos sobre la América (1788); texto ancla de los fundamentos del capitán en cuanto a la situación colonial que confirmará a su arribo en estas tierras:

(...) adquieren -los principios políticos-el rol de un programa, un patrón, una hipótesis de trabajo en torno a la cual es posible desarrollar la segunda fase de la investigación: la experimentación, es decir, la expedición propiamente dicha (Pimentel, 1994:156).

Malaspina comprime en principios las causas/ consecuencias de las medidas aplicadas por el Imperio, evidente en las tensiones posteriores con las minorías ilustradas en América. Antecedente inicial de los movimientos independentistas que derrotarán la posición española, actitud anticipada del proceso que se avecina: el sistema colonial debe modificar el modo de administrar la economía ultramarina, y propiciar una organización equitativa a las demandas de las colonias y generar mayor participación política en decisiones internas. La expedición científicopolítica entonces, es portadora de nuevas teorías 
del conocimiento, intuye otras interpretaciones de la realidad americana9. Por eso, el contacto con los intelectuales criollos es un recurso utilizado por Malaspina en la búsqueda de respuestas que rectifiquen sus principios axiomáticos. Todo ello conforma pruebas suficientes utilizados por el ministro Manuel Godoy para acusarlo de conspiración contra la Corona, debido al peligro que significa que los criollos adquieran algún grado de autonomía. Las puertas se cierra para la difusión de sus memorias porque a su retorno en 1795 fue encarcelado durante siete años; una vez libre retorna a su tierra natal en Italia (muere en 1810). El trabajo en conjunto de la expedición sería publicado posteriormente por el contralmirante Pedro Novo y Colson. ${ }^{10}$

La Guardia Marina tras la reforma en su malla de formación, enfatiza el papel de la ciencia con la renovación de esta parte del conocimiento con la teoría de Newton, esto es, observar el universo entero bajo una ley cósmica: la teoría de la gravitación. En resumen, sus enunciados explican el funcionamiento de lo humano dentro de un orden natural extrapolado a funciones con un trasfondo mecanicista (Pimentel, 150). Malaspina utiliza estos criterios para calificar la expedición con el nombre de "científico-político":

(...) depositó sobre el Nuevo Mundo el sazonado fruto de la Razón ilustrada: la imagen de un Imperio idealmente naturalizado, bien geométricamente al modo mecanicista y cartesiano, bien orgánicamente, como un todo encadenado, un único cuerpo armónico e integrado (Pimentel, 1994: 159).

9 En el Discurso Preliminar que publica anterior al diario oficial del viaje expone: "Emancipadas, digámoslo así, las colonias por manera que deban considerarse una parte alícuota más bien que una parte secundaria de la Monarquía (...)Organizados de este modo los límites y la defensa así externa como interna de cada parte ultramarina de la Monarquía y dejadas a ella misma los medios de atender a su prosperidad local y aquella administración sencilla de policía y de justicia, que jamás pudiera ligarse con una pauta uniforme para todas las provincias, o con una inmutabilidad perpetua, por cuanto varían las circunstancias y las necesidades"(Malaspina en Manfredi, 1994:15).

10 El título del texto es: Viaje político-científico alrededor del mundo por las corbetas Descubierta y Atrevida al mando de los capitanes de navío D. Alejandro Malaspina y Don José de Bustamante y Gierra desde 1789 a 1794 /publicado con una introducción por DON PEDRO DE NOVA Y COLSON, 1885. Madrid: Imprenta de la viuda é hijos de Abienzo.
Los axiomas políticos (Lucena y Pimentel 1991) son diez postulados escritos en similitud a la utilizada por la escritura de Newton: el enunciado (ley) y su explicación. El examen apunta finalmente a encontrar la felicidad nacional, concepto que se retomará más adelante. Las proposiciones más interesantes de destacar son:

a) Reconocer que la monarquía se compone de tres tipos de sujetos que chocan entre sí: el peninsular, el criollo y el indio; oposición debido a políticas económicas y comportamientos diferentes.

b) La insistencia en el fetichismo de los metales (oro y plata), ganan a nivel de producción sólo las colonias los costos son asumidos por la monarquía. Los extranjeros en cambio, diversifican el mercado al explotar otros productos que prometen mejores utilidades. En unión con lo anterior, se advierte lo anticuado de la cartografía que mantiene rutas comerciales marítimas pocos efectivas.

c) Tanto el monopolio como el proteccionismo, destruyen todo intento de levantar ideas nuevas en el área mercantil, por eso Malaspina, critica la riqueza fácil y ostentosa de su tiempo.

\section{LA TRAYECTORIA VISUAL DE JOSÉ DEL POZO}

Las áreas del conocimiento partícipes de este magno proyecto, responden a los principios asignados por el capitán italiano. En este sentido, el conjunto de ilustraciones cumplen con la misión de asumir los caracteres centrales de los lugares-sujetos con los cuales se tuvo contacto (Soler, 1995)11. La finalidad del trabajo es observar qué elementos del arte neoclásico están presentes en los registros visuales de la Patagonia por José del Pozo (1789-1790), y observar cómo su trabajo visual se conecta con el pensamiento malaspiniano, en lo que respecta al enfoque sobre la organización social del indígena austral y su posición en la radiografía del estado político de las colonias americanas.

Malaspina solicitó a Don Francisco de Bruna,

11 Se estipula cerca de 3.000 imágenes repartidas en distintas colecciones de museos, universidades o particulares. El catastro principal se ubica en tres lotes: El Depósito Hidrográfico del Museo Naval en España; la colección Felipe Bauzá, en el Museo de América (Londres) y el Archivo de Real Jardín Botánico (Madrid). Otros depósitos menores: El fondo Bauzá de British Museum (Inglaterra), la colección Bonifacio del Carril (Argentina) y la Universidad de Chile. 
Oidor Decano de la Academia de Sevilla, la recomendación de un pintor sevillano. De acuerdo a su misiva -del 26 de diciembre de 1788-debe reunir algunos requisitos como: fortaleza física, conocer las técnicas de la perspectiva y habilidad descriptiva: "...que representen al vivo aquellos objetos, que ni aun las plumas más lustras pudieran describir cabalmente..." (Carmen Sotos,1982: 67). La cercanía del oidor con el padre de José del Pozo posibilita su embarque hacia América, pues al momento de su nombramiento, es el conserje de la Real Escuela de Bellas Artes en Sevilla, lugar donde su padre (hasta su muerte) ocupó el cargo de director; lo que habla de una tradición familiar ligado al arte español:... excelente sujeto para pintar perspectivas, de muy buena educación, algún caudal de geometría y una gran robustez sobre una edad de 32 años... (Francisco de Bruna, en Sotos, 1982:69).

Del estilo pictórico de José del Pozo, Carmen Sotos menciona la preeminencia por la decoración y el uso del color en el afán de acentuar lo agradable de la vista: fue un buen retratista, un tanto amanerado, pero con un gran defecto: su extraordinaria irregularidad, capaz de hacer trabajos de gran calidad junto a otros que parecen más de un aprendiz que de un pintor de su categoría (Sotos, 1982: 75). Irregularidades que se pueden entender por el contexto de trabajo, ya que el movimiento constante obliga al pintor captar rápidamente los esbozos, las líneas generales de un dibujo que se interrumpe por la situación de tránsito; o bien, se acepta la conjetura del desinterés del pintor a mitad de 1790, que motiva el quiebre con el capitán y su posterior despido.

Si escudriñamos temporalmente el trabajo pictórico de José del Pozo a inicios del siglo XIX (Torre, 1994)12, verificamos una importante carrera artística junto a Matías Maestro en el virreinato de Lima (Kusonoki, 2006: 183-209). Lo interesante, es el grado de versatilidad y acomodo del sevillano para adaptar sus técnicas a los gustos influyentes de los sectores más conservadores de la sociedad colonial limeña, ya que sus creaciones son catalogadas de "barroquismo tardío", a pesar de conocer los principios del arte neoclásico opositor a las manifestaciones barrocas. Por ejemplo, en los frescos del

12 José Del Pozo no retornó jamás a España, a pesar que su contrato estipulaba esta obligación en función a resguardar la estabilidad económica de su numerosa familia.
Cementerio Local y la Escuela de Medicina (1808), ambos pintores detienen los deseos de las escuelas criollas de configurar un clasicismo con referentes locales, cuando recurren a una homogenización del estilo en función del gusto instalado. El uso de la teatralidad y el "carácter frenético", valida el pasado en defensa del orden colonial, muy lejano a su propuesta estética enmarcada en la expedición.

José Torre (Torre, 1994) acude a los pocos escritos que entregan información biográfica del sevillano, así como de las razones de su desvinculación de la expedición luego de casi dos años de navegación. La causa principal es la disminución de su producción pictórica en concordancia con el desaliento expresado por Malaspina:

(...) a pesar de quantas consideraciones, de quantos ruegos y de quantos sacrificios hemos empleado hasta aquí todos los Oficiales, no nos ha sido posible vencer la natural flojera del Pintor Don Josef del Pozo, cuya abilidad natural está más que sobrepujada de una perpetua Oposición al trabajo... (Malaspina en Torre, 1994:49).

Torre hizo un catastro general del trabajo artístico de José del Pozo, en particular los datos técnicos -material utilizado- y las dimensiones. El ordenamiento de su presentación fue utilizado por el Pabellón de la Marina de Guerra Española en la exposición Ibero-Americana en Sevilla (1920-1930). El tamaño de los cuadros no sobrepasa los $65 \mathrm{~cm}$, quizás por la necesidad del dibujante de cambiar rápidamente de lugar como observaremos en un autorretrato del Pozo en el ejercicio de su oficio. Los comentarios críticos de las obras son exiguos, resalta la falta de prolijidad en las terminaciones y que La reunión amistosa con los Patagones es la composición mejor lograda por el pintor sevillano, por su carácter alegórico y lleno de fantasía.

Retornamos al imaginario cultural europeo, afectado por los acontecimientos históricos y filosóficos que impulsa la crisis del arte barroco. El barroquismo fue de enorme utilidad a la Iglesia Católica frente a la irrupción de la Reforma, pues las representaciones pictóricas cooperan en el mantenimiento del poder religioso (su institucionalidad), a través de la ornamentación abundante, la insistencia de temáticas religiosas -la Virgen María- y el misterio de la Trinidad como forma de control y propaganda. El uso excesivo de la emoción (teatral y efectiva) era parte de este proceso. El neoclasicismo 
en cambio, era un modelo que reflejaba el impulso ilustrado de retornar al mundo antiguo con una visión renovada de las ideas platónicas y el pensamiento liberador racionalista. Aspiraba a una armonía de la representación: unir la objetividad cientificista y la aceptación de los valores de la antigüedad (Valdearcos, 2007:1-10). La figuración desplegada debía ser simple, realista y coherente, no era raro entonces, retornar a los estereotipos clásicos en cuanto a las poses o la exigente estilización corporal. En este sentido, los retratos confeccionados por Del Pozo, responden a este imaginario que influye en la percepción visual sobre las colonias americanas, porque el pintor cumple con un conjunto de convenciones (prácticas representacionales) que organiza la visión.

\section{LOS PUENTES ENTRE LA REFLEXIÓN \\ DE ALEJANDRO MALASPINA Y LA DESCRIPCIÓN VISUAL DE LA EXPEDICIÓN EN LA PATAGONIA.}

\section{El espacio patagónico}

El material es una aguada en colores, de $59 x$ $37 \mathrm{~cm}$, cuya fecha de confección es el 2 de diciembre de 1789. Único cuadro que se tiene conocimiento de una vista panorámica del paisaje patagónico creado por Del Pozo.

El cuadro (Fig. 1) nos sitúa en la posición de un testigo que toma nota visual del arribo de las embarcaciones españolas a Puerto Deseado. Mediante el contraste de tamaño -barco/geografía- el sevillano cuantifica la magnitud del paisaje austral. El uso de una paleta de colores análogos en todos sus componentes, responde a la búsqueda de una coherencia compositiva y a la sencillez del trazado según la propuesta neoclásica; aquí la objetividad se apropia de la escena. El autor procura con esta armonía representacional, borrar el carácter exógeno de los barcos y acentuar la naturalidad del paso de autoridades monárquicas por sus reinos ultramarinos. La amplitud de la visión del puerto y los tonos variados del suelo, coincide con la percepción de Malaspina de comprender los cambios geográficos según el punto de vista y la heterogeneidad constitutiva de la tierra:

Desmenuzando más el punto de perspectiva pareció (comprendiendo todos los objetos bajo una rápida mirada) que se presentaban a la vista, en primer término, costas no cubiertas de vegetables verdes y lozanos, sino leñosos, verde-amarillentos, raro. En segundo término, situada en la misma costa y como en aparente dirección NS por las revueltas del puerto, una barranca escarpada, con asurcamientos perpendiculares y manchas blancas. Ya las aguas hurtan a las tierras, ya las tierras a las aguas, y sobresalen varias puntas y ensenadas. Finalmente, tercer término, es el fondo del puerto, en él una barranca blanquisca y una loma en barda (con barranquita blanca en su cresta) en dirección NS en que termine el horizonte (Malaspina en Sagredo y Gonzáles, 2004: 190).

El mar es trazado con leves tintes de color, sin insistir en lo tórrido que históricamente se asigna a su navegación que, Malaspina tempranamente difiere, apuntando a un examen más exhaustivo del comportamiento del mar según el punto geográfico, el comportamiento de las marejadas junto a los momentos estacionales, elementos que varían las condiciones de cabotaje:

Desde esta época la navegación del Cabo de Hornos se nos hizo más bien una de las más placenteras de entre trópicos, que de las penosas, a que la embarcación y el ánimo del navegante están ya (de antemano igualmente) bien dispuesto (Malaspina en Sagredo y Gonzáles, 2004: 194-195).

(...) las puntas de los islotes y costas rechazan sus aguas y le dan mayor violencia. Donde

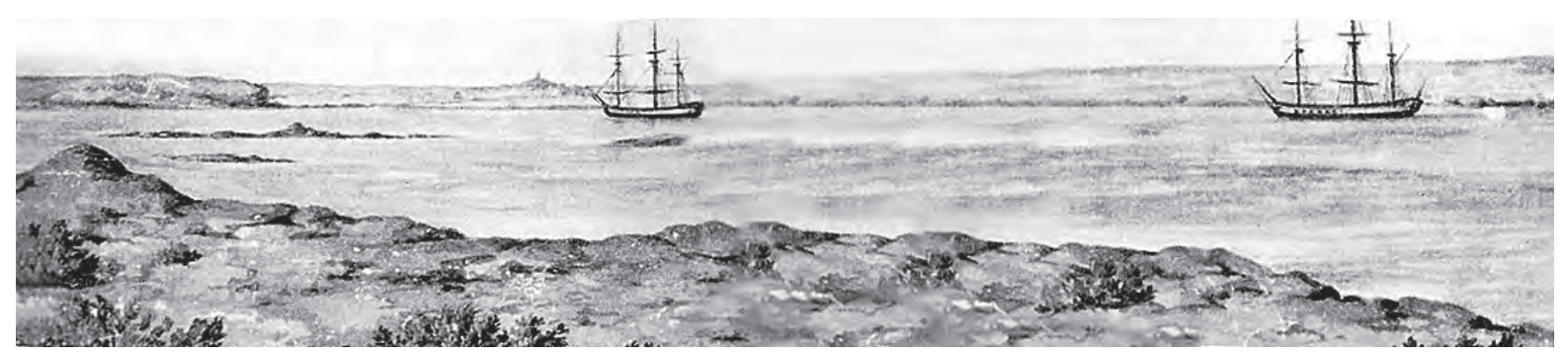

Fig. 1. José del Pozo. Puerto Deseado. Museo Naval. 


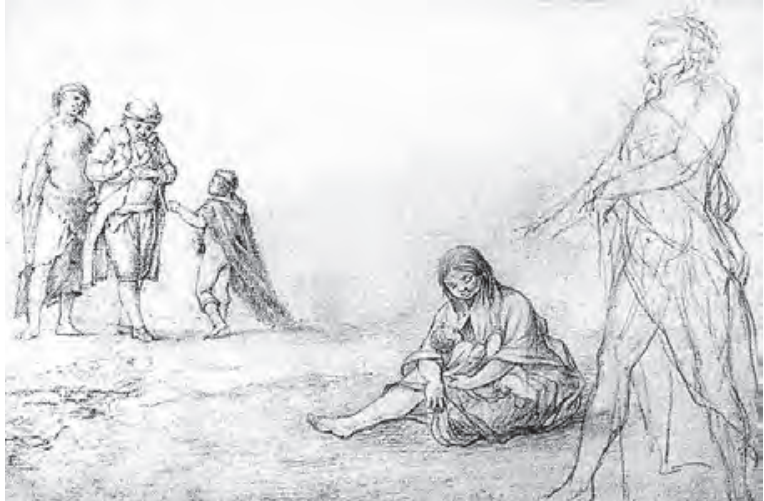

Fig. 2. José del Pozo. Antonio Pineda en la Patagonia.

el cruce ensancha es más suave la corriente. Al abrigo de las islas y ensenadas es casi plácida y serena especialmente en ciertos parajes, donde crecen en abundancia los sargazos (Malaspina en Sagredo y Gonzáles, 2004: 215).

\section{El arquetipo del científico}

El sujeto colonial (colonizador/colonizado) ha sido representado con elementos que marcan su grupo de pertenencia. Por ejemplo, en las primeras imágenes de los españoles (siglo XVI) era común la presencia de la espada (armadura) con los estandartes de la corona, con el fin de visualizar las características del explorador y su acción fundacional en los territorios americanos. En este sentido, el dibujo del naturalista (Fig.2) Antonio de Pineda (Manfredi, 1994: 207) ${ }^{13}$, expone a nivel de proceso de representación los elementos que entran en juego a fines del siglo XVIII:

-La conciencia que en América no hay nada que "descubrir" sino reevaluar lo observado por otros.

-La institución científica adquiere poder progresivamente cuyo sustrato es la razón como herramienta válida de comprender el mundo.

-España en sintonía con los demás países europeos inicia un proceso de cuestionamiento a las concepciones básicas de la sociedad, en un camino de transformación a nivel de escala de valores. En

13 Antonio Pineda y Ramírez (1753-1792) murió antes de retornar a España; era oficial de marina de la Armada española en la que, desempeñó el trabajo de naturalista. Sus descripciones fueron utilizadas por Malaspina en la redacción del diario oficial.

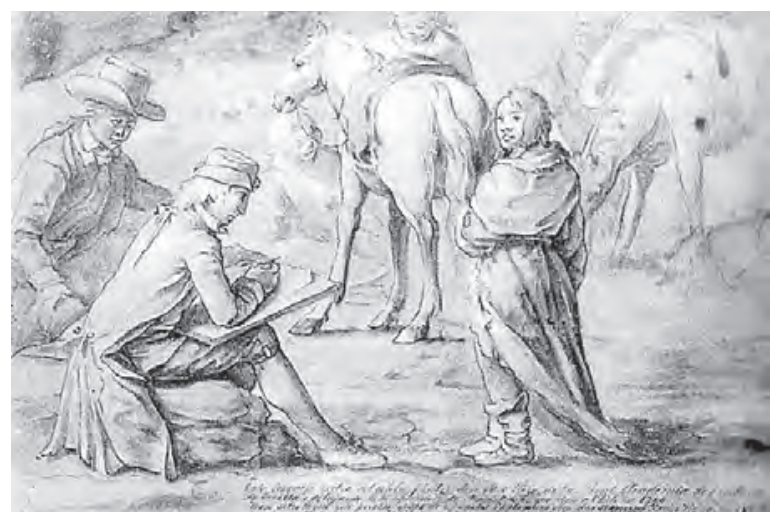

Fig. 3. José del Pozo retratando a una india patagona. Museo Naval.

esta mentalidad emergente sobresalen sujetos que encarnan estos cambios entre ellos, el científico.

De acuerdo con Susana López, el científico en la Patagonia cumple el destino de: un héroe ejemplar, capaz de abrir las puertas del futuro, iluminando cada rincón del mundo; los viajeros incansables funcionan como metáfora de la razón, buscando las certezas y erigiendo el progreso como modo hegemónico de relacionarse con otras formas de la cultura (López, 2003: 77). La función de Pineda en la expedición, es estudiar en profundidad el espacio y sus habitantes para reemplazar las formas simbólicas coloniales por otros criterios a luz de procedimientos empíricos: observar, cuantificar y deducir, por lo tanto, del Pozo delinea el arquetipo clave en el siglo XIX. El científico construye un discurso donde los indígenas mantengan una posición asimétrica frente al europeo. Su acción en el hacer y decir posiciona una visión legitimadora de su oficio, porque los criterios de su estudio son avalados por la razón. La retórica progresista acentuada con el positivismo (XIX), será el lenguaje común en la intelectualidad de la época: estructurar un espacio de conocimiento de la realidad por medio de la medición empírica de los fenómenos observados, y junto con este ejercicio mantener el control.

Los cuadros que encabezan este apartado (Fig. 2 y Fig. 3), tienen en común la exposición del trabajo en terreno -del pintor y el científico- con la colaboración de informantes. La participación activa del indígena, es representada por el pintor con la niña posando y en los gestos de conversación de los tehuelches con el naturalista, concentrado en transcribir tal relato en su diario: 
Pedimos al cacique se dejase retratar, y lo concedió sin repugnancia, permitiendo que nuestro pintor don José del Pozo lo situase a propósito, obedeciendo a cuanto este efecto se le prevenía; se hizo lo mismo con una joven de dieciocho años, que sobresalía entre las demás por su viveza, no mal parecer y facilidad en comprender cuanto se le explicaba, trasladando de su idioma al castellano algunas voces, de las cuales el naturalista don Antonio Pineda formó un pequeño vocabulario (Malaspina en Sagredo y González, 2004: 176).

Los retratos del cacique Junchar y de Cátama (Fig. 4, Fig. 5 y Fig. 6) son de una factura simple y firme en la delineación de sus contornos. Del Pozo no acude a ninguna recreación del espacio, su concentración apunta únicamente a la constitución del rostro y el cuerpo, sin caer en exageraciones. A modo de zoom, observamos las particularidades del patagón al replicar los dibujos de Junchar en una misma posición. El primer retrato es un plano general, destacando la vestimenta típica de la comunidad tehuelche (el uso de pieles y el listón en el cabello) como la expresión de vigor a pesar de la edad del cacique (60 años) (Fig. 5). En el segundo, detiene su atención en el rostro, en las arrugas como el color mate de la piel, unido al carácter pensativo que connota pasividad. La disposición física del modelo proviene de un tratamiento escultórico que el pintor asume del neoclasicismo, con el fin de exaltar en forma clara y precisa ciertos valores: la envergadura física del patagón, pero sin caer en el gigantismo (Fig. 4).

En el cuadro de Cátama (Fig. 6), el pintor ejerce las mismas autoexigencias en su formulación. Detener la imagen en una pose que signifique un concepto preciso, sin caer en ambigüedades. La posición de sus manos sugiere la feminidad y junto con ello, resaltar la misma tranquilidad del cacique Junchar. El orden de la vestimenta y el cuidado del peinado eliminan el sentido de salvaje de la visión europea sobre la comunidad patagona. No obstante, es el trabajo titulado "Reunión amistosa de los patagones" en el cual el pintor expresa su visión general de la composición social del indígena, las muestras de felicidad a pesar de lo adverso de la geografía.

Aclaremos el término de felicidad, concepto que preocupa a los países europeos en el examen de la situación del hombre en el mundo; particularmente, cuando el movimiento crítico proyecta las visiones del aparato burgués, que asocian la felicidad a las aspiraciones individuales de mejorar las condiciones de vida (legitimar la propiedad privada y el bienestar económico) (Diz, 2000: 349-380).

(...) la razón lleva al hombre a la búsqueda del interés, cuya realización conduce a la felicidad, término que se identifica con la riqueza y el bien-

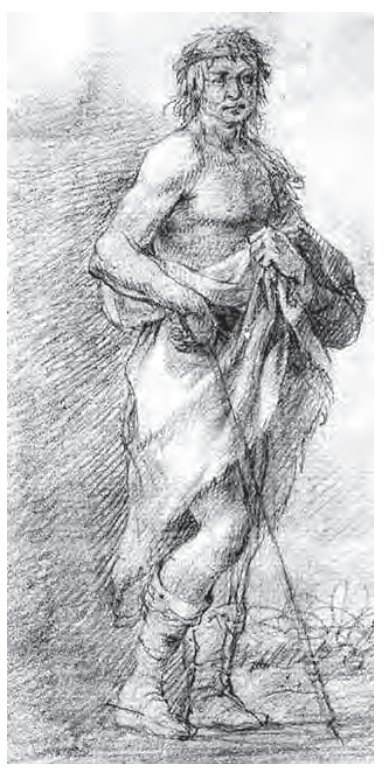

Fig. 4. Cacique Junchar.

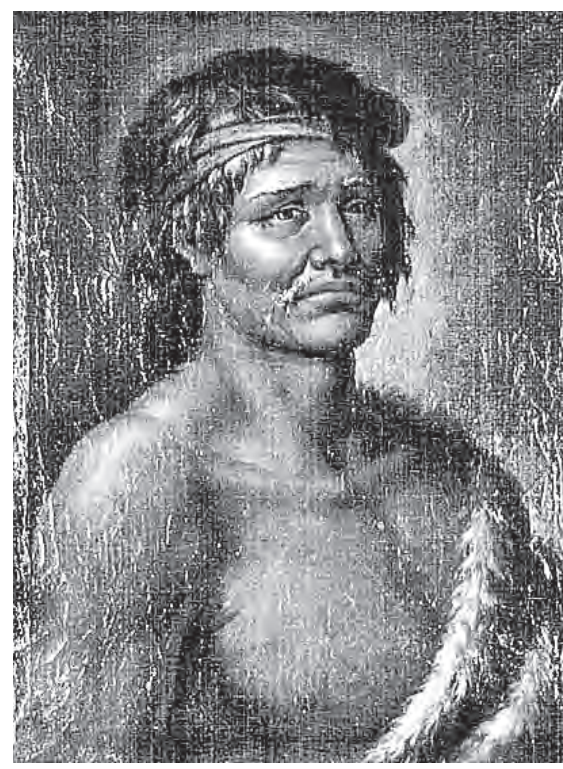

Fig. 5. Cacique Junchar.

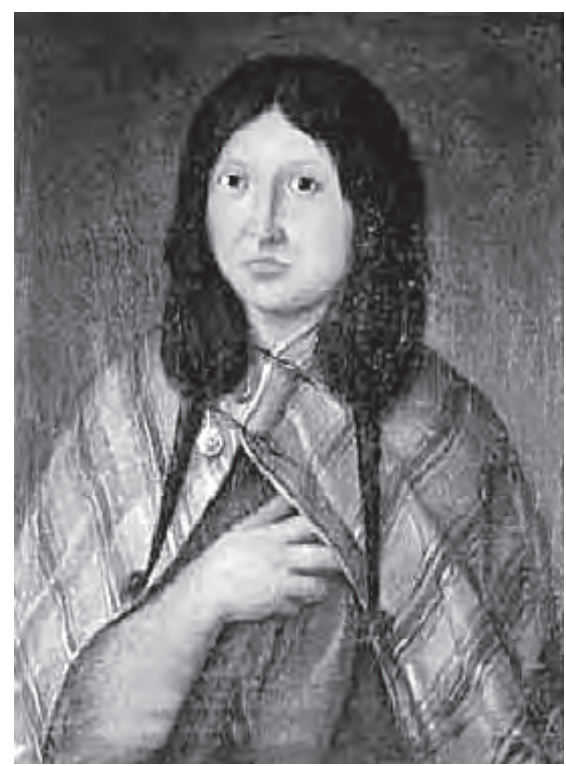

Fig. 6. Cátama. 
estar material, tanto individual como colectivo. Todo ello se acabará teorizando políticamente y se convertirá en defensa de un derecho de todos los hombres a alcanzar la felicidad (que en gran parte se identificará a partir de entonces con un bienestar material), base de partida de los posteriores cambios igualitarios democráticos (Diz, 200:350).

La reflexión de Malaspina sobre la naturaleza humana del tehuelche evita la extralimitación del gigante colonial, y lo sitúa en la armonía de proporciones, simetría que se traslada a la descripción de sus lazos filiales, que difiere con la brutalidad (salvajismo) asignado a los pueblos originarios:

(...) una honestidad cual se ha notado particularmente en las mujeres, pueden servir de modelo a los pueblos más civilizados, no menos que su natural bondad y confianza con que se entregan al trato de los extranjeros, manifestando en este hecho su buena fe, la que en ocasiones les ha traído graves perjuicios (Malaspina en Manfredi, 1994: 212).

Del Pozo representa al indígena (Fig. 7) en una actitud reposada, de paz en el encuentro con el extranjero. Los niños son retratados como pequeños querubines extraídos de un cuadro clásico, emplazados en las costas australes. El canon neoclásico en la representación del indígena del sur va más allá de un sentido estético, es lograr dar una explicación del porqué la presencia de hombres sosegados en tal precarias condiciones. La respuesta se encuentra en parte en la teoría del buen salvaje. Sujeto que constituye el estado natural que el hombre extravió por la incorporación de la propiedad privada, cuyo camino es la degradación del núcleo social. Malaspina retoma estos argumentos para responder la razón de la felicidad del patagón a pesar de estar lejos de las "pautas de civilización". La conclusión es que

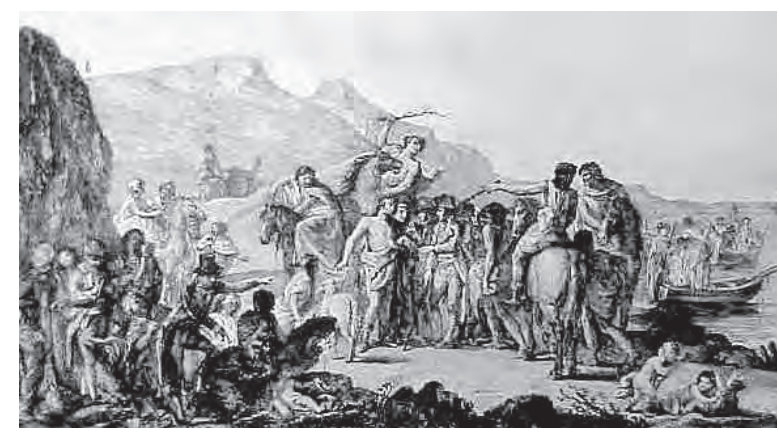

Fig. 7. Reunión amistosa con los patagones. el patagón es la encarnación de la forma primitiva del hombre civilizado, el origen incontaminado de la sociedad:

(...) si la ignorancia de los conocimientos propios del género humano y de las comodidades y seguridad que ofrece una junta civilizada tan natural al hombre, no fuesen un obstáculo según nuestras ideas para ser feliz, pocos hombres se hallan en mejor proporción para llamarse dichosos y estar contentos con su suerte como los Patagones: disfrutan de los esenciales bienes de la sociedad sin sujetarse al sinnúmero de penalidades que una demasiado refinada trae consigo; gozan de una salud robusta hija de su sobriedad, y de que no conocen aquellos envenenados orígenes de tantos males, la gula y la lujuria: tienen una anchurosa libertad en satisfacer sus limitados apetitos, que no son más porque por fortuna suya son cortas sus ideas, y como el terreno que habitan les da espontáneamente su alimento, no acosados por un trabajo perpetuo y necesario, pasan los días felices en una tranquila ociosidad y reposo, que es su pasión dominante y el seguro fruto de la combinación de todas sus circunstancias, y no de ineptitud o natural estupidez, como han pretendido muchos (Malaspina en Manfredi, 1994: 336).

Representar el acto de colaboración del tehuelche, habla de una elaboración "participativa" en la comprensión de su propia sociedad por medio del ejercicio racional, que desmiente visualmente la radicalidad del salvaje de los escritos anteriores. Uno de esos puntos, es el papel de la madre, mención reiterativa en el texto de Malaspina y en los cuadros del pintor, el amor profesado a sus hijos sorprende a la expedición, porque es capaz de abandonar sus labores cotidianas en la urgencia de consolar a sus pequeños:

El amor de las mujeres a sus hijos, y la consecuente subordinación de éstos a sus padres, y en general a todos los ancianos, se nos hizo visible en todas las ocasiones en los cuales concurrimos con ellos en el bergantín Carmen. Las encontramos una tarde que habían puesto sus niños a dormir en un camarote inmediato a la cámara, se sobresaltaban al menor ruido que hiciesen y al despertarlos y traerlos consigo les daban mil besos, prorrumpiendo (según se conocía) en muchas expresiones del cariño más tierno hacia ellos (...) (Malaspina en Sagredo y Gonzáles, 2004: 226). 


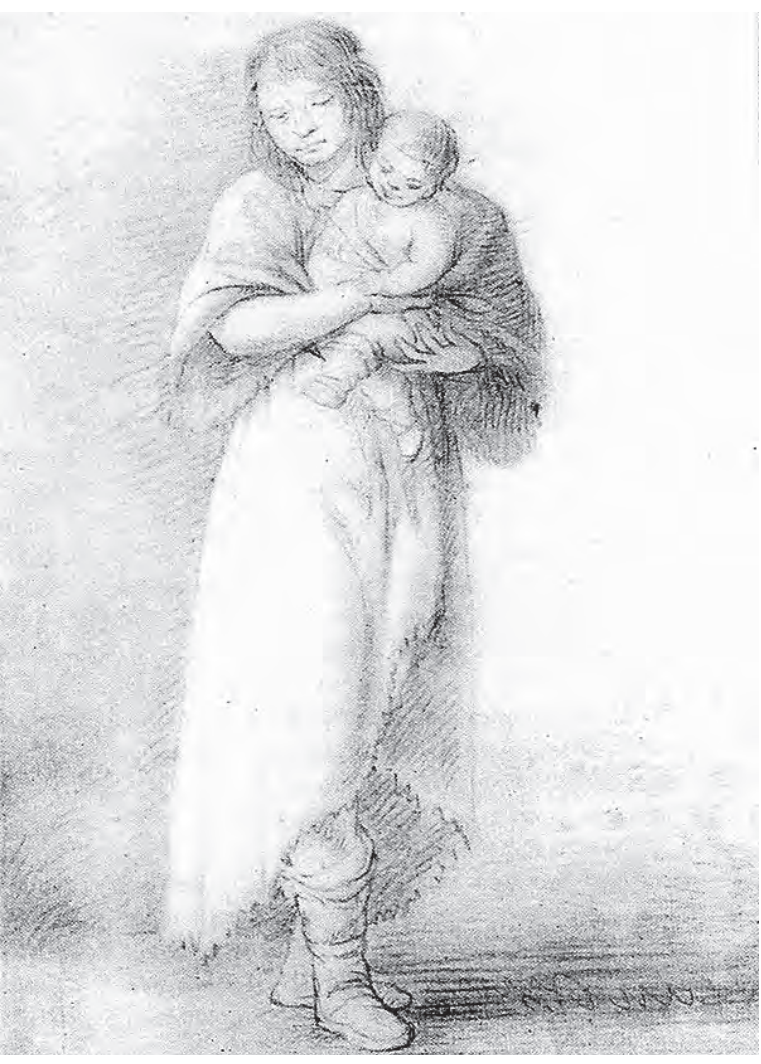

Fig. 8. José del Pozo. India Patagona.

\section{Mito del gigante}

El gigante patagón es una referencia recurrente en crónicas e informes de viaje tras la nominación asignada por Antonio Pigafetta (Enrique Pato, 2005:1-10) $)^{14}$. Lo particular del mito, es que había un consenso para considerar la zona austral como regio gigantum, imagen que se mantuvo hasta el siglo XVIII ${ }^{15}$, ya que el europeo afirma la monstrificación del indígena del sur, ya sea por su aspecto físico o sus prácticas culturales (Carreño, 2008: 127-146).

(...) los monstruos son expresiones del pecado de ser lo otro, forman parte de una información

14 El autor sintetiza tres interpretaciones en torno a la figura del patagón de acuerdo a su origen (literario); EISENBERG D. Inexactitudes y misterios bibliográficos: las primeras ediciones de Primaleón. Letradura, 1997 (13):173-178; (lingüístico) GONZÁLEZ, J.R., 1999. Patagonia-patagones: orígenes novelescos del nombre. Buenos Aires: Emecé y (etnográfico) LIDA DE MAKIEL, M.R. Para la toponimia argentina: Patagonia. Hispanic Review, 1952 (20):321-323.

15 Por ejemplo, la expedición francesa de Louis Antoine Boungainville en 1767 y la inglesa de John Byron (1764-1766). general sobre lo extraño, introducen el exotismo y simbolizan el paganismo. Por otro lado, lo monstruoso solo existe en relación a un orden establecido como oposición a una cultura superior, es decir, lo monstruoso representa la asimétrica relación que existe entre la "naturaleza americana" y la "civilización europea" (Carreño, 2008: 129).

El estudio de Livon-Grossman (2004), reconstruye la formación del mito patagónico a través de las expediciones para identificar los momentos que considera centrales para aprehender la zona como un todo. Según el autor, la inscripción del mito tiene un carácter fundacional porque retrata el territorio con una doble condición: primigenio-vacía y como proyecto de integración a la nación. Concluye que los textos de viajes operan con un efecto acumulativo, unidos a ciertas lógicas discursivas: la referencia de un espacio común, apelar a fuentes anteriores (para afirmar o corregir), e interpretar el paisaje. En Pigafetta, resalta el exotismo y la categoría de desierto que moldea el imaginario europeo con respecto a la Patagonia, descripción que persiste en narraciones posteriores:

El gigantismo de los indígenas patagónico es inmortalizado por Pigafetta al quedar para siempre asociado al nombre tanto como a las dimensiones del lugar: gigantes son los indígenas, gigante el territorio en el que viven, gigantes las ideas que se asocian a ese espacio (Livon-Grossman, 2004: 41).

El proyecto reflexivo ilustrado coloca en discusión las razones del porqué el tamaño del indígena patagón. Preguntas como, si la proporción del gigante es una determinación del espacio, o su envergadura física es debido a que ambas integran la matriz primitiva de la humanidad, son cuestiones que despiertan en este período a buscar en las culturas pasadas o lejanas el lugar en donde encontrar la pureza moral extraviada.

La ilustración quiere refundar un nuevo sentido para el mundo que tenga asidero en la tradición clásica, así surge el tópico del Paraíso. El Paraíso sustenta los fundamentos de la cultura occidental, es el espacio idílico de la recreación bíblica que el hombre extravía por comer del árbol del conocimiento (Leiva, 2004: 133-149). Con Rousseau, este concepto retorna al "orden natural" es decir, a su materialización dentro de los límites históricos. Con la alineación diacrónica del desarrollo humano busca en el mundo ese espacio idílico en oposición 
a la idea de progreso, que según el pensador francés, alejó al hombre de esta concepción originante. En este sentido, el "buen salvaje" responde a esta visión incólume en oposición a la degradación de la vida moderna:

Rousseau se opone al enciclopedismo, a la cultura y sus manifestaciones en la medida que se restringe las potencialidades humanas, desfigurando la propia imagen construida, destruyendo el ideal de felicidad al que la humanidad estaba destinada en su estado prístino (Leiva, 2004: 139).

Existen entonces, dos miradas contrapuestas de la situación del indígena patagón en el siglo XVIII: el imaginario del gigante y el buen salvaje, discusiones que Malaspina debido a su formación conoce en detalle ${ }^{16}$, por eso aventura a dar un paso más allá de estas formulaciones. La monstrificación del indígena es desplazada en las primeras hojas de su informe mediante las mecánicas cientificistas: medir al indígena, observar las formas de organización social y notificar sus resultados. Así construye argumentos sólidos, sustentados en la "razón" empírica que afirma la inexistencia del gigante:

Se midió la talla al cacique, resultado de seis pies 10 pulgadas de Burgos, correspondiendo a la robustez de sus miembros y abultadas facciones, pero todos muy semejantes en lo fornidos, pudiendo asegurarse que aunque no deben pasar por gigantes, como quisieron suponer algunos viajeros, son generalmente de una talla y corpulencia muy superior a los europeos" (Malaspina en Sagredo y Gonzáles, 2004: 176).

Respecto a la concepción del buen salvaje la acepta, pero, refuerza esta propuesta hacia el terreno de lo económico-político: afirmar que no existen razones fundadas para mantener una colonia en el sur por los costos de manutención, y las decisiones económicas deben ir en función a un ordenamiento efectivo-útil tanto para la colonia como a la monarquía.

Es difícil desenvolver la verdad filosófica sobre lo acaecido en nuestros ensayos harto costosos e infelices para poblar la costa patagónica.

16 En Malaspina es evidente el amplio conocimiento de las distintas crónicas que relataron su paso por la tierra patagónica. De igual forma, el trabajo de Juan Pimentel que hemos citado anteriormente, se refiere a las lecturas del capitán de las teorías del pensamiento francés, entre ellos Rousseau.
Las discordias intestinas y los intereses particulares de los muchos que han concurrido a esa empresa dejan en duda tal vez indisoluble si lograron o prometieron lograr de una próspera vegetación los granos sembrados en el puerto San Julián y en el Deseado. Puede a lo menos asegurarse que nunca han prosperado en el puerto de San José y que aún en las orillas del río Negro, los productos ni son proporcionados al clima, ni al riego que fecundiza el suelo (Malaspina en Sagredo y Gonzáles, 2004: 223).

La pregunta central del espíritu pensador de Malaspina es ¿se puede administrar una economía útil para la monarquía en el espacio patagónico? Respuesta que se comienza avizorar al final del diario.

\section{CONCLUSIONES GENERALES}

Investigar las directrices centrales perseguida por la expedición de Malaspina, permitió articular los imaginarios sociales y las representaciones (textuales y visuales) en la comprensión -más allá de su materialización discursiva-, de las coincidencias y divergencias con los imaginarios sociales pre-existentes como, de aquellos en procesos de formación que representarán a la Patagonia durante el siglo XIX. Un punto a destacar, es el grado de legitimidad que alcanza la función práctica del científico en la visión de Malaspina: obtener información bajo otras bases que desplacen la imagen del explorador colonial por el indagador de la realidad, a través de la razón. La retórica ilustrada articulada en el alero de nuevas teorías europeas, influye en la constitución del imaginario en el sur, ya que el relato científico aspira a crear un tipo de conocimiento sobre el espacio patagónico y sus habitantes. El método empírico genera lecturas de carácter objetivo que logra la verosimilitud anhelada por la institucionalidad científica; en este sentido, el arquetipo del científico en la práctica de su oficio, ejerce una forma de observar los fenómenos. La crónica de Malaspina y el trabajo visual de José del Pozo anticipa estos criterios, aceptan como verdad aquello que es válido por el procedimiento y la coherencia visual, un espacio inexpugnable para quienes existen en las categorías impuestas. Los distintos procedimientos, medir al patagón o forzarlo a posturas estatuarias, son maneras de relacionarse y sobre todo, instaurar un conocimiento respecto al territorio austral del continente. 
Si nos interrogamos sobre el papel de la representación en la confección de los imaginarios sociales como base de sentido, las preguntas que intentamos dar respuesta fueron ¿Cómo vincular los estudios visuales y textuales en el análisis de los imaginarios sociales en la Patagonia? ¿Cuáles fueron sus características y de qué manera se expresaron? ¿Qué repercusiones tienen las representaciones a nivel de constitución de un imaginario patagónico a fines del siglo XVIII?

Por lo tanto, el trabajo pictórico de José del Pozo materializa por medio del arte neoclásico la representación del imaginario dieciochesco en España; especialmente, la concordancia con los postulados científicos-políticos del capitán Alejandro Malaspina sobre la descripción del indígena patagón. Malaspina delinea un proyecto distinto a sus antecesores, busca reflexionar en la posibilidad de abandonar la Patagonia como objeto de deseo constante, por otros criterios que ahuyenten los miedos infundados de la Corona de una apropiación extranjera. La posición malaspiniana, acepta que el patagón es feliz porque tiene "cortas ideas" impuestas por el medio que habita; lo virtuoso se da justamente por su lejanía de los centros metropolitanos. Qué necesidad tiene entonces, el hombre de "progreso", de anhelar un espacio generador de grupos humanos detenidos en un tiempo primitivo. Las "cortas ideas" son fruto de una geografía que no alienta nada más que la felicidad del "bárbaro", no es posible adaptar una colonia europea a un paisaje adverso, ni sus habitantes a una estructura civilizadora; así, insistir en el establecimiento político-administrativo en la tierra patagónica no tiene sentido para el capitán italiano.

\section{BIBLIOGRAFÍA}

BAEZA, MANUEL ANTONIO. 1995. Los caminos invisibles de la realidad social. Ensayo de sociología profunda sobre los imaginarios sociales. Chile: Ril editores.

BHABHA, Homi K. El mimetismo y el hombre. La ambivalencia del discurso colonial. El lugar de la cultura, 2002: 111119. Buenos Aires: Manantial

CARREÑO, GASTÓN. El Pecado de Ser Otro. Análisis a algunas representaciones monstruosas del indígena americano (siglo XVI-XVIII). Revista Chilena de Antropología [en línea]. Diciembre 2008 (12): 127-146. http://www.antropologiavisual.cl/imagenes12/imprimir/carreno_imp.pdf
DIZ, ALEJANDRO. Nueva axiología de la España del siglo XVII en el contexto europeo. Cuad. Dieciocho, 2000 (1): 349-380. España: Ediciones Universidad de Salamanca

GÓMEZ, PEDRO ARTURO. Imaginarios sociales y análisis semiótico. Una aproximación a la construcción narrativa de la realidad. Cuad. Fac. Humanid. Cienc. Soc. [en línea] 2001, (17): 195-209. Argentina: Universidad Nacional San Salvador de Jujuy. http://www.scielo.org.ar/scielo.php?script=sci_arttext\&pid=S1668 $81042001000200012 \& \operatorname{lng}=e n \& n r m=i s o>$.

INSTITUTO PANAMERICANO DE GEOGRAFÍA E HISTORIA. 2001. La gran expedición española de Alejandro Malaspina en América, 1789-1795. México, D.F: Comisión de historia, Tomo I.

KUSONOKI, RICARDO. Matías Maestro, José del Pozo y el arte en Lima a inicios del siglo XIX Fronteras de la historia. Bogotá, Colombia: Instituto Colombiano de Antropología e Historia. ICANH, 2006 (11): 183-209.

LEIVA, GONZALO. El paraíso y sus naturales: visión de Chile en la cartografía y el grabado (siglos XVII-XIX). Intus Legere, 2004 (Vol. 2, 7): 133-149. Santiago de Chile: Universidad Adolfo Ibáñez. Facultad de Humanidades.

LIVON-GROSSMAN, ERNESTO. 2004. Geografías imaginarias. El relato del viaje la construcción del espacio patagónico. Rosario: Beatriz Viterbo.

LÓPEZ, SUSANA. 2003. Representaciones de la Patagonia. Colonos, científicos, políticos (1874-1914). La Plata: Ediciones al margen.

LUCENA, MANUEL y PIMENTEL, JUAN. 1991. Axiomas políticos sobre la América. Madrid: Doce Calles, D.L.

MANFREDI, DARÍO. 1994. Alejandro Malaspina: La América imposible. Madrid: Compañía Literaria.

MINISTERIO DE DEFENSA, MUSEO NAVAL. 1987. La expedición Malaspina 1789-1794. Madrid: Lunwerg editores.

PATO, ENRIQUE. De nuevo sobre el origen de patagones. Monografía.com [en línea]. 2005:1-10. http://www. monografia.com/trabajos16/patagones.html

PIMENTEL, JUAN. 1994. Ciencia y política en el pensamiento colonial de Alejandro Malaspina (1754-1794). Madrid: Universidad de Complutense de Madrid. Facultad de geografía e historia (tesis doctoral)

SAGREDO, RAFAEL y GONZÁLES, JOSÉ. 2004. La expedición Malaspina en la frontera austral del imperio español. Santiago de Chile: Editorial Universitaria. Centro de Investigaciones Diego Barros Arana.

SOLER, EMILIO. Fernando Brambila, pintor de cámara de Carlos IV. Españoles en Italia e italianos en España. IV Encuentro de investigadores de las universidades de 
Alicante y Macerata [en línea]. Mayo 1995. http://www. cervantesvirtual.com.

SOTOS, CARMEN. 1982. Los pintores de la expedición de Alejandro Malaspina. Madrid: Real Academia de la Historia.
TORRE, JOSÉ. 1994. Los artistas pintores de la expedición Malaspina. Buenos Aires: Universidad de Buenos Aires. VALDEARCOS, ENRIQUE. El arte neoclásico y Francisco de Goya. CLIO 33 [en línea]. 2007: 1-10. http://www. clio.rediris.es 